\title{
Technical Note: Comparison of simulated ground nest types for grazing/tram- pling research
}

\author{
LAURA PAINE, D.J. UNDERSANDER, DAVID W. SAMPLE, GERALD A. BARTELT, AND TRACY A. SCHATTEMAN
}

Authors are research specialist and professor, Department of Agronomy, University of Wisconsin, 1575 Linden Drive, Madison, Wisc. 53706; and grassland ecologist, section chief, and seasonal technician, Wisconsin Department of Natural Resources Bureau of Research, 1350 Femrite Drive, Monona, Wisc. 53716.

\begin{abstract}
Ornithologists often use simulated nests consisting of game bird or domestic poultry eggs to study nest survival. Researchers investigating cattle trampling of ground nests have sometimes used clay targets instead of actual eggs to avoid the confounding effects of nest depredation. To determine whether livestock respond similarly to clay targets and egg nests, we compared inadvertent trampling and intentional disturbance of clay targets versus clutches of 3 pheasant eggs by Angus $\times$ Holstein heifers. Overall trampling levels for clay turget- and egg-nests were similar (35 and $36 \%$, respectively). Cattle noticed and responded to both types of nests. When noticed, simulated nests were kicked, sniffed, licked, or picked up in the mouth. Cattle disturbed an average of $25 \%$ of the clay targets and $8 \%$ of the egg nests during 4 trials. Our results suggest that cattle are as likely to inadvertently trample egg nests as they are clay targets, but targets are more likely to attract attention and are therefore disturbed more often than egg nests. The greater likelihood of intentional disturbance of clay targets by cattle reduces the confidence of extrapolating the fate of this type of simulated nest to that of actual nests.
\end{abstract}

Key Words: artificial nests, cattle, clay targets, dummy nests, game birds, intensive rotational grazing, IRG, nest survival

Simulated nests are commonly used to study the effects of predation and other factors on nest survival (Henry 1969). Use of simulated nests ensures an adequate sample size for statistical testing, eliminates time-consuming nest searching, and allows study of some aspects of avian breeding ecology without disturbing nesting birds.

\footnotetext{
The authors thank the following people for their support of this sudy: Tim Wood and Dan Peschel, Lancaster Agricultural Research Station; Jim Keir, Todd Peterson, Alan Crossley, and Don Bates, Wisconsin DNR; Bruce Craig, University of Wisconsin College of Agricultural and Life Sciences Statistical Consulting Service.

Partial funding for this study was provided by the Federal Aid in Wildlife Restoration Act under Pittman-Robertson Project W-160-P, the Wisconsin Department of Natural Resources, the University of Wisconsin-Madison, Department of Agronomy and the University of Wisconsin Agricultural Experiment Stations.

Manuscript accepted 28 May 1996.
}

Most frequently, researchers use eggs of domestic poultry or pen-reared game birds to simulate ground nests (Henry 1969, Horkel et al. 1978, Bareiss et al. 1986). Where clutches of eggs are used as simulated nests for cattle trampling research, predation can confound estimates of trampling damage (Koerth et al. 1983, Bareiss et al. 1986). Some researchers have used clay pigeon shooting targets to simulate ground nests because they do not attract predators, but are as fragile as eggs, providing evidence of trampling (Koerth et al. 1983, Jensen et al. 1990). The appearance and odor of clay targets are unlike natural nests; these characteristics may result in a different animal response when nests are encountered in the pasture (N.J. Silvy, Texas A\&M Univ., pers. commun.).

We conducted this study to determine which simulated nest type would be more appropriate for a planned study of ground nest trampling under intensive rotational grazing in the midwestern United States (Paine et al. 1996). During the nesting season, vegetation height in rotationally grazed, cool-season grass pastures varies from 5 to $40 \mathrm{~cm}$. Nesting species include those that nest in sparse cover such as killdeer (Charadrius vociferus L.) as well as those that require more dense cover such as pheasant (Phasianus colchicus L.). Our objective was to determine if inadvertent and intentional disturbance of clay targets by cattle is similar to that of simulated nests of pheasant eggs, and if these simulated nest types can be used interchangeably.

\section{Study Area and Methods}

This study was conducted at the University of Wisconsin's Lancaster Agricultural Research Station (LARS) in southwestern Wisconsin. A 2.4 ha pasture, of approximately 15\% slope was used. Pasture vegetation included smooth bromegrass (Bromus inermis L.), orchard grass (Dactylis glomerata L.), quackgrass (Agropyron repens L.), Kentucky bluegrass (Poa pratensis L.), and red clover (Trifolium pratense L.). The trial was conducted in late April 1993, when vegetation was $<10 \mathrm{~cm}$ in height.

One hundred twenty nest sites were located in a 10 by 12 row grid in the pasture. Nest sites were about $12 \mathrm{~m}$ apart. We randomly placed 60 of each nest type on the grid. Nest types were a 10 - 
cm diameter clay pigeon shooting target, placed paint side down; or a clutch of 3 unwashed pheasant eggs. Nest density was 50 nests $\mathrm{ha}^{-1}$, much higher than has been recorded for natural nests (Buhnerkempe 1979, George et al. 1979). No effort was made to create a "nest bowl" or to conceal the simulated nests in vegetation. The purpose of the study design was not to simulate natural conditions, but to ensure cattle would encounter nests in the pasture so intentional and inadvertent animal disturbance of the 2 nest types could be assessed.

The grazing treatment was applied using LARS's herd of 130 Angus $\times$ Holstein heifers. The resulting stocking density of 54 animal units $(\mathrm{AU}) \mathrm{ha}^{-1}$ is typical of an intensive rotational grazing system for dairy cattle (Undersander et al. 1991). The cattle occupied the pasture for 7 hours each day on 2 consecutive days. Two nest observations wcre madc each day following rumination (trials 1 and 3) and grazing periods (trials 2 and 4). The herd was let into the pasture each morning at approximately 0900 and, after a period of exploration and grazing, settled down to ruminate. Nest checks for trials 1 and 3 were made after about 5 hours, when the cattle began grazing in early afternoon. Trials 2 and 4 ran from the start of afternoon grazing until late afternoon. Nest checks for trials 2 and 4 were made after the cattle had grazed for about 2 hours and were removed from the pasture.

We recorded 1 of 3 fates for each nest: trampled, disturbed, or intact. Targets that were broken into several pieces were recorded as trampled. Targets were recorded as disturbed if they were flipped over, moved from their original grid position, chipped or were covered with saliva, mud, and pieces of grass. For egg nests, the number of eggs crushed was recorded. For comparison with targets, an egg nest with $\geq 1$ eggs crushed was considered trampled. Egg nests were recorded as disturbed if $\geq 1$ eggs were moved from the nest site, were separated within the nest site, or were covered with saliva, mud, and pieces of grass. After each nest check, we replaced nests that were disturbed or trampled, so the number of intact nests would be equal at the start of each trial.

Each trial was analyzed separately and nest types were compared for trampled, disturbed, and intact nests using a simple Zstatistic formula, with significance at $P<0.05$. Because trials varied in length, we also compared hourly rates of trampling and disturbance during each of the 4 trials using the Z-statistic with significance at $P<0.05$.

\section{Results and Discussion}

\section{Trampling Damage}

While there were differences in trampling damage among the 4 trials, we recorded similar overall totals for the 2 nest types. Total amounts of trampling damage for the 4 trials were $36 \%$ and $35 \%$ for the egg nests and clay targets, respectively. Trampled targets were most often smashed into many pieces, whereas egg nests had varying levels of damage. Approximately two-thirds of trampled egg nests had $\geq 1$ of the 3 eggs intact; half of these had 2 of the 3 eggs intact (data not shown).

For trials 1 and 4, the number of egg nests and targets that were trampled were similar (Fig. 1a). Slightly less than half of the 60 nests of each type were trampled during each of these trials. For trial 2, the number of targets trampled (25\%) was more than
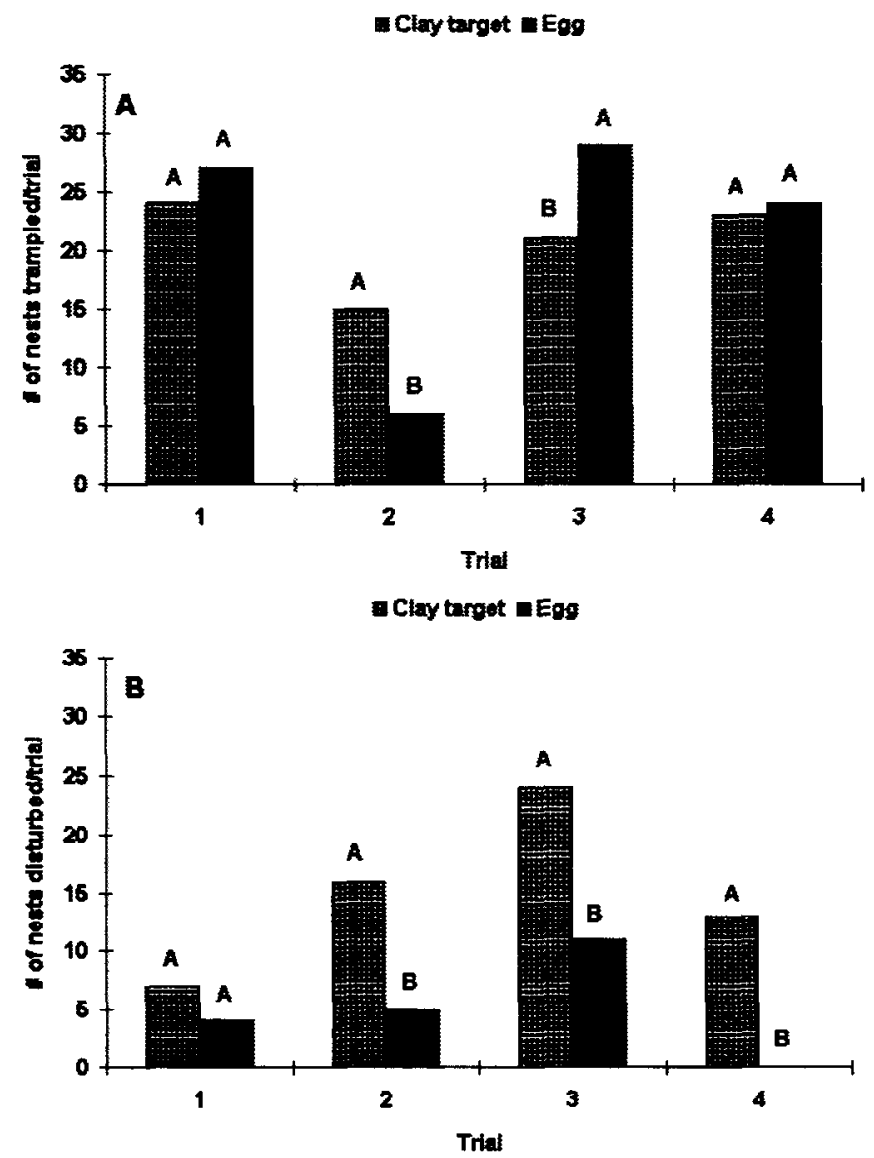

Fig. 1. Total number of simulated nests trampled (A) or disturbed (B) during 4 grazing trials. Nest types were a clay target (hatched bar) or a clutch of 3 unwashed pheasant eggs (solid bar). For each trial, 60 of each nest type were located randomly within a grid in a 2.4 ha. paddock. Differing letters within trials indicate significant differences (P $\leq 0.05)$ by LSD.

twice the number of egg nests trampled (10\%); however, for trial 3 , more egg nests (48\%) were trampled than targets (35\%). These results suggest that chance plays a major role in inadvertent trampling of ground nests.

For all trials except trial 2 , trampling rates per hour were similar for targets and egg nests. In trial 2 , we recorded a greater trampling rate per hour for targets than for egg nests (Fig. 2a). Animal inactivity during this trial resulted in a lower total number of trampled targets and egg nests compared to the other trials. Differences both in trampling rates and in overall damage among trials reflect the randomness of individual animal grazing/ruminating behavior and movement within the pasture (Smith et al. 1986).

\section{Nest Disturbance}

Cattle were observed to notice and respond to both types of nests. Both targets and eggs were sniffed, licked, or occasionally picked up in the mouth. One animal's interest in a simulated nest often attracted the attention of nearby animals. We informally observed 30 instances of cattle disturbance of nests. Of these, 23 were instances of cattle investigating targets, picking them up in their mouths and carrying them from the nest site. We observed 7 

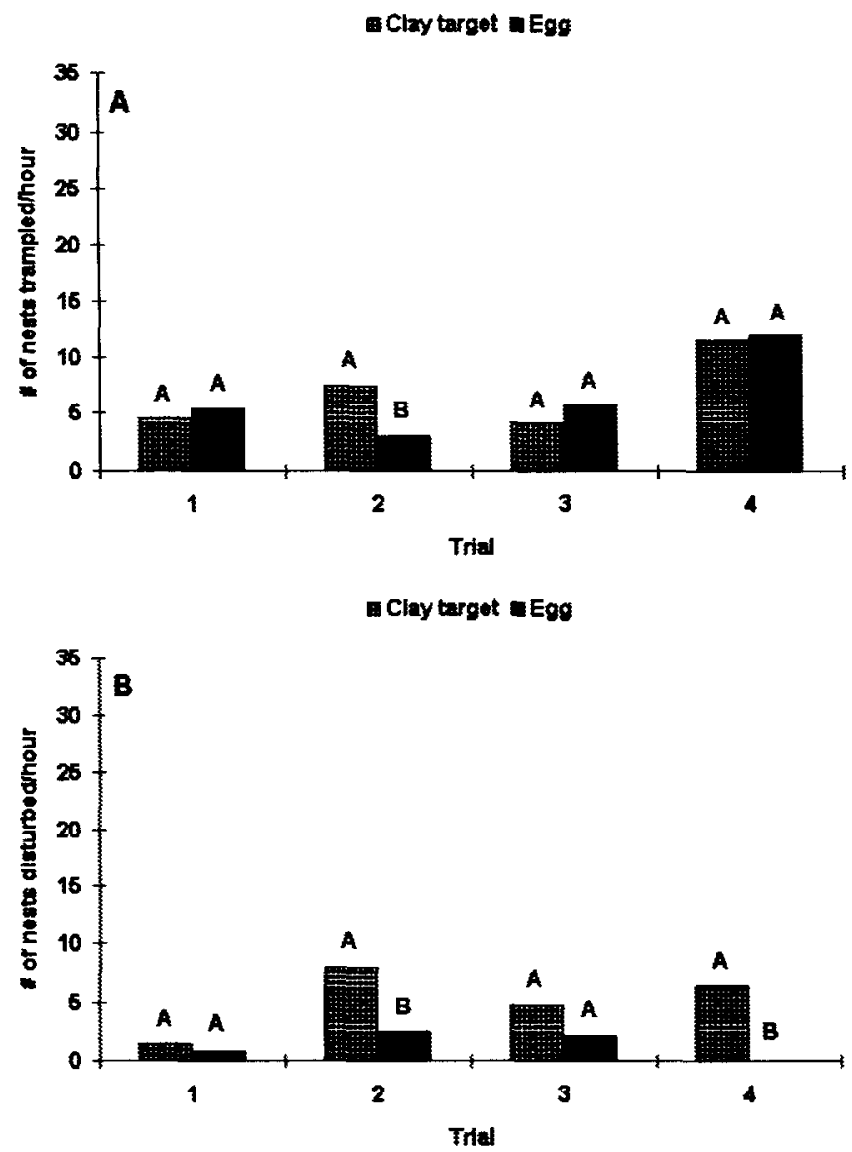

Fig. 2. Number of simulated nests trampled (A) or disturbed (B) per hour during 4 grazing trials. Nest types were a clay target (hatched bar) or a clutch of 3 unwashed pheasant eggs (solid bar). For each trial, 60 of each nest type were located randomly within a grid in a 2.4 ha. paddock. Differing letters within trials indicate significant differences $(P \leq 0.05)$ by LSD.

instances of egg nests attracting such attention. In some cases, cattle picked up individual eggs in their mouths and moved them several feet from the nest site without damaging them.

Nest check data support our informal observations of nest disturbance (Fig. 1b). For all trials, more targets than egg nests were disturbed. Disturbance of targets was $>3$ times higher than egg nests in both afternoon trials ( 2 and 4$)$. For trial $3,>2$ times as many targets were disturbed as egg nests. For trial 1, the difference was not significant. Overall, $25 \%$ of the target nests were disturbed in the 4 trials, compared to $8 \%$ of egg nests.

In general, hourly rates of disturbance during the afternoon trials were higher than during the morning trials (Fig. 2b). The hourly rate of disturbance of targets was significantly higher than that of egg nests for the afternoon trials but not for the morning trials. During the morning trials, which encompassed a rumination period, the cattle were less likely to encounter simulated nests in the paddock because they were inactive. During the afternoon trials, the herd was actively grazing and was more likely to encounter simulated nests. The higher level of disturbance of targets than egg nests during active grazing suggests that clay targets are more likely to be noticed by grazing cattle than are egg nests.

\section{Trampling and Disturbance Patterns}

There were no obvious spatial patterns of nest trampling or disturbance either within a trial or among trials. One hundred eleven of the 120 nest sites (93\%) were trampled or disturbed $\geq 1$ times during the 4 trials. At 40 of the 120 nest sites, 2 trampling or disturbance events were recorded during the 4 trials. One and 3 events were recorded at 27 and 34 nest sites, respectively, and less than $10 \%$ of the sites had 4 events recorded. Within the grid of 120 nest sites, 9 sites (7\%) were never trampled during the 4 trials. The locations of these sites within the grid appeared random, suggesting that chance was responsible for their survival.

\section{Conclusions}

In this comparison of clay pigeon shooting targets and clutches of pheasant eggs used as simulated ground nests, we found more clay targets were intentionally disturbed than egg nests, whereas inadvertent trampling of the 2 nest types was similar. The heifers in our study appeared to take a particular interest in clay targets when encountered in pastures. Both our recorded nest disturbance data and our informal observations suggest that unconcealed simulated nests of pheasant eggs attracted less attention than clay targets. We conclude the use of clay targets as simulated nests may generate biased data in rotationally grazed, cool-season grass pastures in the Midwest. The disturbance of clay targets by cattle reduces the confidence with which one can extrapolate from the fate of this type of simulated nest to that of natural ground nests.

\section{Literature Cited}

Bareiss, LoJ., P. Schulz, and F.S. Guthery. 1986. Effects of short-duration and continuous grazing on bobwhite and wild turkey nesting. $J$. Range Manage. 39:259-260.

Buhnerkempe, J.E. 1979. Habitat utilization and partitioning within a community of nesting grassland birds. M.S. Thesis, Eastern Illinois University, Charleston, Ill. $58 \mathrm{pp}$.

George, B.J., A.L. Farris, C.C. Schwartz, D.D. Humburg, and J.C. Coffey. 1979. Native prairie grass pastures as nest cover for upland birds. Wildl. Soc. Bull. 7:4-9.

Henry, V.G. 1969. Predation on dummy nests on ground-nesting birds in the southern Appalachians. J. Wildl. Manage. 44: 806-813.

Horkel, J.D., R.S. Lutz, and N.J. Silvy. 1978. The influence of environmental parameters on nesting success of upland game birds. Proc. Ann. Conf. Southeast. Assoc. Fish Wildl. Agencies. 32: 234-241.

Jensen, H.P., D. Rollins, and R.L. Gillen. 1990. Effects of cattle stock density on trampling loss of simulated ground nests. Wildl. Soc. Bull. 18:71-74.

Koerth, B.H., W.M. Webb, F.C. Bryant, and F.S. Guthery. 1983. Cattle trampling of simulated ground nests under short duration and continuous grazing. J. Range Manage. 36:385-386.

Paine, L., D.J. Undersander, D.W. Sample, G.A. Bartelt, and T.A. Schatteman. 1996. Cattle trampling of simulated ground nests in rotationally grazed pastures. J. Range Manage. 49:294-300.

Smith, B., P.S. Leung, and G. Love. 1986. Intensive grazing management: forage, animals, men, profits. Pp. 93-105. The Graziers Hui, Hawaii.

Undersander, D.J., B. Albert, P. Porter, and A. Crossley. 1991. Pastures for profit: A guide to rotational grazing. Univ. Wis. Coop. Ext. Publ. \#A3529, Madison, Wis. 36 pp. 